\title{
Human papillomavirus genotype prevalence in invasive penile cancers from a registry-based United States population
}

\section{Brenda Y. Hernandez ${ }^{1}$ *, Marc T. Goodman ${ }^{1}$, Elizabeth R. Unger ${ }^{2}$, Martin Steinau ${ }^{2}$, Amy Powers ${ }^{1}$, Charles F. Lynch ${ }^{3}$, Wendy Cozen ${ }^{4}$, Maria Sibug Saber ${ }^{4}$, Edward S. Peters ${ }^{5}$, Edward J. Wilkinson ${ }^{6}$, Glenn Copeland ${ }^{7}$, Claudia Hopenhayn ${ }^{8}$, Youjie Huang ${ }^{9}$, Meg Watson $^{10}$, Sean F. Altekruse ${ }^{11}$, Christopher Lyu ${ }^{12}$, Mona Saraiya ${ }^{10}$ and The HPV Typing of Cancer Workgroup ${ }^{1}$}

1 University of Hawaii Cancer Center, University of Hawaii, Honolulu, HI, USA

${ }^{2}$ Division of High-Consequence Pathogens and Pathology, National Center for Emerging and Zoonotic Infectious Diseases, Centers for Disease Control and

Prevention, Atlanta, GA, USA

${ }^{3}$ Department of Epidemiology, College of Public Health, The University of lowa, lowa City, IA, USA

${ }^{4}$ Departments of Preventive Medicine and Pathology, USC Keck School of Medicine, Norris Comprehensive Cancer Center, University of Southern California, Los Angeles, CA, USA

${ }^{5}$ Department of Epidemiology, School of Public Health, Louisiana State University Health Sciences Center, New Orleans, LA, USA

${ }^{6}$ Department of Pathology, Immunology, and Laboratory Medicine, College of Medicine, University of Florida, Gainesville, FL, USA

${ }^{7}$ Michigan Department of Community Health, Lansing, MI, USA

${ }^{8}$ Department of Epidemiology, College of Public Health, University of Kentucky, Lexington, KY, USA

${ }^{9}$ Florida Department of Health, Tallahassee, FL, USA

${ }^{10}$ Division of Cancer Prevention and Control, National Center for Chronic Disease Prevention, and Health Promotion, Centers for Disease Control and Prevention, Atlanta, GA, USA

"Division of Cancer Control and Population Sciences, National Cancer Institute, Rockville, MD, USA

${ }_{12}$ Battelle Memorial Institute, Durham, NC, USA

Edited by:

Silvia De Sanjose, Catlan Institute of Oncology, Spain

Reviewed by:

Elisabeth Couto, Norwegian Knowledge Centre for the Health

Services, Norway

Laia Alemany, Catalan Institute of Oncology, Spain

Hugo De Vuyst, International Agency for Research on Cancer, France

*Correspondence:

Brenda Y. Hernandez, University of Hawaii Cancer Center, 701 llalo

Street, Honolulu, HI 96813, USA e-mail: brenda@cc.hawaii.edu
Background: Human papillomavirus (HPV) is estimated to play an etiologic role in $40-50 \%$ of penile cancers worldwide. Estimates of HPV prevalence in U.S. penile cancer cases are limited.

Methods: HPV DNA was evaluated in tumor tissue from 79 invasive penile cancer patients diagnosed in 1998-2005 within the catchment areas of seven U.S. cancer registries. HPV was genotyped using PCR-based Linear Array and INNO-LiPA assays and compared by demographic, clinical, and pathologic characteristics and survival. Histological classification was also obtained by independent pathology review.

Results: HPV DNA was present in 50 of 79 (63\%) of invasive penile cancer cases. Sixteen viral genotypes were detected. HPV 16, found in $46 \%$ (36/79) of all cases (72\% of HPVpositive cases) was the most prevalent genotype followed equally by HPV 18,33 , and 45 , each of which comprised $5 \%$ of all cases. Multiple genotypes were detected in $18 \%$ of viral positive cases. HPV prevalence did not significantly vary by age, race/ethnicity, population size of geographic region, cancer stage, histology, grade, penile subsite, or prior cancer history. Penile cases diagnosed in more recent years were more likely to be HPV-positive. Overall survival did not significantly vary by HPV status.

Conclusion: The relatively high prevalence of HPV in our study population provides limited evidence of a more prominent and, possibly, increasing role of infection in penile carcinogenesis in the U.S. compared to other parts of the world.

Keywords: human papillomavirus, HPV, prevalence, penile cancer, United States

\section{INTRODUCTION}

The annual, average age-adjusted incidence of invasive penile cancer in the U.S. is less than 1 per 100,000, which represents less than $0.5 \%$ of all cancers in men (1). Penile cancer incidence varies globally, with lower incidence in the United States and other Western countries and comparably higher incidence in parts of Africa, Southeast Asia, and Latin America (2, 3). Human papillomavirus
(HPV) likely represents a distinct etiologic pathway of penile carcinogenesis (4). Worldwide, HPV is estimated to play an etiologic role in $40-50 \%$ of penile cancers $(2,3,5)$. HPV 16 is the most frequently detected genotype in penile tumors $(2,6,7)$. Other risk factors for penile cancer include cigarette smoking, lack of circumcision, poor hygiene, and phimosis $(4,8-11)$. The extent to which worldwide differences in penile cancer incidence are attributed to 
variation in HPV prevalence is unknown. There is some evidence of regional differences in HPV prevalence in penile tumors (2). To date, however, there are limited estimates of the prevalence of HPV in U.S. penile cancer patients. In U.S. studies, including small case series from single institutions and single geographic regions, prevalence ranged from 31 to $82 \%(12-15)$.

\section{MATERIALS AND METHODS}

We conducted a study to evaluate the genotype-specific HPV distribution in invasive penile cancer cases from the U.S. and to compare the viral status of cases by demographic, clinical, and pathologic characteristics. This evaluation was part of a larger initiative by the Centers for Disease Control and Prevention (CDC) to examine HPV genotype distribution among anogenital and select head and neck cancer sites for cases diagnosed in the United States prior to the implementation of widespread HPV prophylactic vaccination (16). This study was approved by the institutional review boards overseeing the CDC and participating cancer registries. Invasive penile cancer cases were defined based on the International Classification of Diseases for Oncology Version 3 (17). Cases were selected from patients with histologically confirmed invasive penile cancer who were diagnosed in Kentucky, Louisiana, Michigan, Iowa, Hawaii, and Los Angeles County. Additionally, Florida included a three-county catchment area. Penile cancer cases from Iowa, Hawaii, and Los Angeles County were selected from those with archival tissue in existing tissue repositories. The three residual tissue repositories (RTR) (18) are a part of the National Cancer Institute's (NCI) surveillance, epidemiology, and endresults (SEER) program and consist of collections of deidentified formalin-fixed paraffin-embedded (FFPE) tumor tissue specimens obtained from area pathology laboratories. Penile cancer cases from Florida, Kentucky, Louisiana, and Michigan were sampled from all invasive cases diagnosed in 2004-2005 with available FFPE tissue from area pathology laboratories. Penile cases from Hawaii included all RTR cases diagnosed in 2000-2004; Iowa and Los Angeles County cases included those diagnosed in 19982000. A total of 163 penile cancer cases were initially identified across the seven registries and tumor tissue specimens were available for 90 .

Formalin-fixed paraffin-embedded tissue specimens from the 90 cases were prepared at central laboratories servicing each registry or medical facility following a uniform protocol. As previously detailed, one representative block from each case was prepared using procedures to minimize the risk of sample-tosample contamination (16). Sections were prepared from each block using a new disposable blade for each case. The first and last sections were stained with hematoxylin and eosin (H\&E) and intervening sections were transferred into $2 \mathrm{ml}$ conical tubes (Simport, Beloeil, Canada). Prepared FFPE tissues were sent to the CDC. H\&E sections were reviewed by a study pathologist (Elizabeth R. Unger) to confirm the presence of malignancy. The first H\&E slide was digitized using ScanScope XT (Aperio Technologies, Vista, CA, USA) at $0.25 \mathrm{hm}$ per pixel resolution, equal to $40 \times$ objective. Of the 90 cases prepared, 5 lacking adequate tumor tissue and 2 with only in situ components were excluded.
Tissue from the remaining 83 cases was genotyped. One suitable tissue sample from each case was processed as previously described using high temperature assisted tissue lysis (19) and automated DNA purification with a Chemagic MSM1 (PerkinElmer, Waltham, MA, USA). The resulting $100 \mu \mathrm{l}$ DNA elute was tested immediately or stored at $-20^{\circ} \mathrm{C}$ until testing. A blank sample without tissue was included in every sample batch to monitor potential cross contamination. All DNA extracts were tested with the Linear Array HPV Genotyping Test (LA, Roche Diagnostics, Indianapolis, IN, USA), which distinguishes 37 different HPV genotypes $(6,11,16,18,26,31,33,35,39,40,42,45,51$, 52 (XR), 53, 54, 55, 56, 58, 59, 61, 62, 64, 66, 67, 68, 69, 70, 71, 72, $73,81,82,83,84,89$, IS39). Templates for the PCR reaction were prepared with $10 \mu \mathrm{l}$ DNA and $40 \mu \mathrm{l} \mathrm{H}_{2} \mathrm{O}$, otherwise following the manufacturer's protocol. The reverse line-blot hybridization was performed with an automated platform; Beeblot instruments (Bee Robotics, Caernarfon, UK). Samples with negative or inadequate LA results were re-tested with the INNO-LiPA HPV Genotyping Assay (LiPA, Innogenetics, Gent, Belgium), which detects $29 \mathrm{HPV}$ types including three types not covered by the Linear Array (43, 44,74, ) and performs a generic probe to identify other HPVs not on the array (HPV X). The assay was performed according to the manufacturer's specifications using an Autoblot 3000 (MedTec, Buffalo Grove, IL, USA) for the line-blot procedure. Both typing assays included an endogenous positive control for the presence of amplifiable DNA. Samples negative for HPV and for the control probe in both assays were considered inadequate. Of the 83 penile cancer cases genotyped, 4 yielded inadequate results and were excluded.

A total of 79 cases were retained in the statistical analyses. Deidentified demographic (age, sex, population size), clinical (year of diagnosis, history of other cancers), pathologic (subsite, stage, grade), and outcome data (vital status, cause of death, survival time) were available from each registry. Stage was based on the SEER staging classification system (20). A large number of cases were histologically classified as unspecified squamous cell carcinoma (SCC). To improve the reliability of histological classification, digital images of all cases were reviewed and re-classified by one pathologist (Amy Powers) who was blinded to clinical and pathologic information as well as HPV status of cases.

Statistical analyses were conducted using SAS version 9.2. All tests were two-sided and a $p$-value of 0.05 was considered to be statistically significant. Overall HPV prevalence was based on the detection of one or more HPV genotypes in tumor tissue. Multiple genotypes detected in a case were not counted more than once in prevalence estimates. HPV 16, 18, 31, 33, 35, 39, 45, 51, $52,56,58,59,66$, and 68 were considered high-risk genotypes (21). All other genotypes were considered to be of low or undetermined risk. Age was imputed to the mid-point of 5 year age groups for three cases from whom single year age was not available. Race/ethnicity was classified as non-Hispanic white, non-Hispanic black, Hispanic, and other. Comparisons by HPV status were made using the Chi-square test for discrete variables. Overall survival of HPV-positive and HPV-negative patients was compared using Kaplan-Meier and multivariable Cox regression analyses. Survival analyses excluded five cases for which vital status and survival time were not available. 
Table 1 | Genotype distribution of HPV DNA-positive invasive penile cancer cases $(n=50)$.

\begin{tabular}{lc}
\hline HPV types & Number of cases \\
\hline 6 & 1 \\
$16^{\mathrm{a}}$ & 29 \\
$18^{\mathrm{a}}$ & 2 \\
$33^{\mathrm{a}}$ & 3 \\
$35^{\mathrm{a}}$ & 1 \\
42 & 1 \\
$45^{\mathrm{a}}$ & 2 \\
$52^{\mathrm{a}}$ & 1 \\
$6,16^{\mathrm{a}}$ & 1 \\
$16^{\mathrm{a}}, 45^{\mathrm{a}}$ & 1 \\
$16^{\mathrm{a}}, 55$ & 1 \\
$16^{\mathrm{a}}, 58^{\mathrm{a}}$ & 1 \\
$16^{\mathrm{a}}, 18^{\mathrm{a}}, 72$ & 1 \\
$16^{\mathrm{a}}, 18^{\mathrm{a}}, 31^{\mathrm{a}}, 58^{\mathrm{a}}, 73$ & 1 \\
$16^{\mathrm{a}}, 45^{\mathrm{a}}, 55$ & 1 \\
$33^{\mathrm{a}}, 62$ & 1 \\
$35^{\mathrm{a}}, 53,59^{\mathrm{a}}$ & 1 \\
$X^{\mathrm{b}}$ & 1 \\
\hline
\end{tabular}

a High-risk types; all others are considered to be of low or undetermined risk.

${ }^{b} \mathrm{HPV}$-positive for none of the 40 types assayed.

\section{RESULTS}

Human papillomavirus DNA was detected in 50 of 79 (63\%) invasive penile cancer cases. A total of 16 genotypes were detected (Table 1). HPV 16 was the most prevalent genotype comprising $72 \%(36 / 50)$ of HPV-positive cases, or 36 of $79(46 \%)$ of all cases. Other high-risk types detected were HPV18, 31, 33, 35, 45, 52, 58 , and 59. Two tumors were solely positive for low-risk types, HPV 6 and HPV 42, respectively. In total, genotypes other than HPV 16 or 18 were prevalent in 12 of 79 (15\%) cases, or $24 \%$ of all HPV-positive tumors. One case was not positive for the 40 genotypes assayed and was designated HPV X. Multiple genotypes were found in 18\% ( 9 of 50) of HPV-positive cases; HPV 16 was detected in 7 of these 9 cases.

Demographic and clinical characteristics of the 79 invasive penile cancer cases study cases in the study sample were comparable to that of all registry cases diagnosed over the same time period (data not shown). Study cases spanned a wide age range; 33-100 years (mean $70.9 \pm 14.8$ ). Whites comprised $56 \%$ of cases followed by blacks (24\%), and Hispanics (17\%). The large majority of cases were diagnosed in 2004-2005 (86\%). Most cases were localized, early stage tumors $(67 \%)$, and of moderately differentiated grade $(51 \%)$. Thirty-two percent of tumors were of the glans or prepuce. A prior history of cancer was reported in $43 \%$ of cases; information on type of cancer was not available. Based on registry data, 61 of the $79(76 \%)$ cases were histologically classified as SCCs not otherwise specified (SCC NOS), 17 were keratinizing SCC and 1 verrucous SCC. NOS cases consisted of those without histological subtype documented in the pathologic record. Following independent pathologic review, cases were re-classified as keratinizing SCC $(n=53)$, basaloid SCC $(n=3)$, warty SCC $(n=3)$, mixed basaloid-keratinizing SCC $(n=4)$, mixed warty-keratinizing SCC
Table 2 | Characteristics of invasive penile cancer cases by HPV status $(n=79)$.

\begin{tabular}{|c|c|c|c|c|c|}
\hline \multirow[t]{2}{*}{ Characteristics $^{\mathrm{a}}$} & \multicolumn{2}{|c|}{$H P V-(n=29)$} & \multicolumn{2}{|c|}{$\mathrm{HPV}+(n=50)$} & \multirow[t]{2}{*}{$P^{b}$} \\
\hline & No. & $\%^{c}$ & No. & $\%^{c}$ & \\
\hline \multicolumn{6}{|l|}{ AGE AT DIAGNOSIS (YEARS) } \\
\hline \multirow[t]{2}{*}{ Mean (SD) } & 72.7 (SD & & 69.8 (SD & & 0.40 \\
\hline & 15.3) & & 14.5) & & \\
\hline$<60$ & 4 & 21.1 & 15 & 78.9 & 0.27 \\
\hline $60-79$ & 14 & 41.2 & 20 & 58.8 & \\
\hline$\geq 80$ & 11 & 42.3 & 15 & 57.7 & \\
\hline \multicolumn{6}{|l|}{ RACE/ETHNICITYd } \\
\hline White & 15 & 37.5 & 25 & 62.5 & 0.77 \\
\hline Black & 5 & 29.4 & 12 & 70.6 & \\
\hline Hispanic & 5 & 41.7 & 7 & 58.3 & \\
\hline \multicolumn{6}{|c|}{ POPULATION SIZE OF RESIDENCE } \\
\hline$<20,000$ & 16 & 32.0 & 34 & 68.0 & 0.42 \\
\hline $20,000-250,0000$ & 3 & 33.3 & 6 & 66.7 & \\
\hline $250,000 \geq 1,000,000$ & 8 & 50.0 & 8 & 50.0 & \\
\hline \multicolumn{6}{|l|}{ YEAR OF DIAGNOSIS } \\
\hline 1998-2003 & 7 & 63.6 & 4 & 36.4 & 0.05 \\
\hline 2004-2005 & 22 & 32.4 & 46 & 67.6 & \\
\hline \multicolumn{6}{|l|}{ STAGE $^{\mathrm{e}}$} \\
\hline Localized & 15 & 31.9 & 32 & 68.1 & 0.10 \\
\hline Regional or distant metastasis & 12 & 52.2 & 11 & 47.8 & \\
\hline \multicolumn{6}{|l|}{ HISTOLOGYf } \\
\hline Keratinizing SCC & 23 & 43.4 & 30 & 56.6 & 0.19 \\
\hline Basaloid or warty SCCg & 2 & 18.2 & 9 & 81.8 & \\
\hline Other SCC & 4 & 26.7 & 11 & 73.3 & \\
\hline \multicolumn{6}{|l|}{ TUMOR GRADE } \\
\hline Well-differentiated & 10 & 43.5 & 13 & 56.5 & 0.46 \\
\hline Moderately differentiated & 12 & 34.3 & 23 & 65.7 & \\
\hline Poorly differentiated & 6 & 54.5 & 5 & 45.5 & \\
\hline \multicolumn{6}{|l|}{ SUBSITE } \\
\hline Glans/prepuce & 10 & 40.0 & 15 & 60.0 & 0.68 \\
\hline Other or unspecified & 19 & 35.2 & 35 & 64.8 & \\
\hline \multicolumn{6}{|c|}{ HISTORY Of OTHER CANCERS } \\
\hline No & 16 & 35.6 & 29 & 64.4 & 0.81 \\
\hline Yes & 13 & 38.2 & 21 & 61.8 & \\
\hline
\end{tabular}

${ }^{a}$ Missing data: race/ethnicity $(n=7)$; population size of residence $(n=4)$; stage $(n=9)$; grade $(n=10)$.

${ }^{b}$ Chi-square test comparing HPV - and HPV+.

c\% Of total for each variable category (row).

${ }^{d}$ Whites and blacks include non-Hispanics only; Asians excluded due to frequencies $<5$.

${ }^{e}$ Stage classified according to SEER Summary Stage 2000.

${ }^{\dagger}$ Based on independent review by one pathologist.

${ }^{g}$ Includes tumors with basaloid or warty types combined with other histologies.

$(n=1)$, and verrucous SCC $(n=1) ; 13$ remained SCC NOS $(n=13)$.

The detection of HPV (any genotype) in penile cancers did not significantly vary by age, race/ethnicity, population size of geographic region, stage, histology, grade, penile subsite, or cancer history (Table 2). Of penile cancers diagnosed during the most 


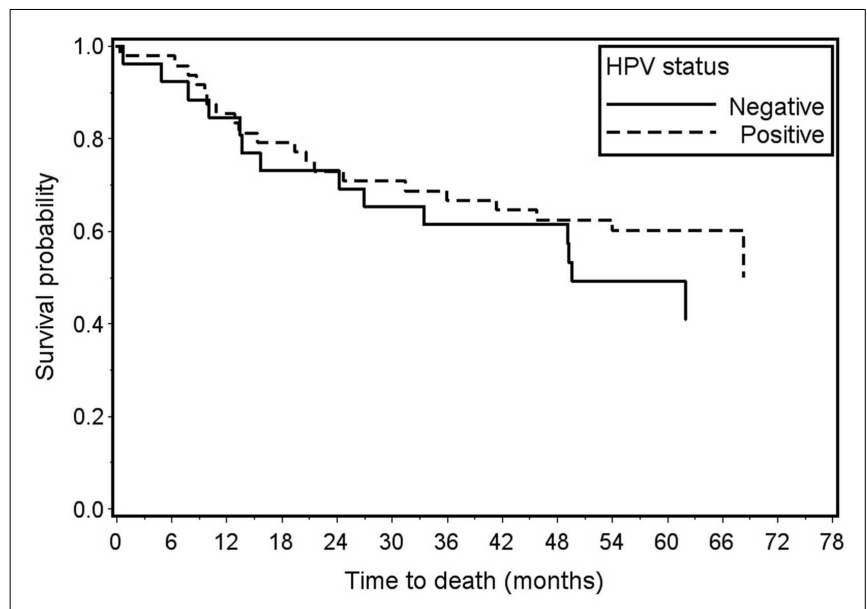

FIGURE 1 | Overall survival of invasive penile cancer cases by HPV status: any HPV+ $(n=48)$ vs. HPV- $(n=26)$ Log-rank $p$-value $=0.37$

recent time period (2004-2005), 68\% were HPV-positive compared with $36 \%$ of cases diagnosed in 1998-2003 $(p=0.05)$. In order to evaluate the possible influence of the age of specimens on the detection of HPV, we compared the number of samples with negative or inadequate results generated from the linear array test requiring retesting with the second assay by period of diagnosis. Four of 11 cases diagnosed in 1998-2003 were derived by LiPA compared to 10 of 67 cases diagnosed in 2004-2005 ( $p=0.09$ ).

Survival analyses included 74 of the 79 penile cancer cases; 5 cases without available outcome data were excluded. Overall survival was $60 \%$ for HPV-positive cases and 50\% for HPV-negative cases $(\log$-rank $p$-value $=0.37)$ (Figure 1). Survival did not vary significantly by HPV status when limited to high-risk types or HPV 16 alone (data not shown). Proportional hazards assumptions were met. For any HPV, the unadjusted hazard ratio was $0.73,95 \%$ CI $0.37-1.45$. After adjustment for age, stage, and year of diagnosis, the hazard ratio was $0.86,95 \%$ CI $0.40-1.86$. In both univariate and multivariate models, high-risk HPV and HPV 16 status did not predict survival (data not shown).

\section{DISCUSSION}

This is the first study of HPV prevalence in invasive penile cancer cases drawn from diverse regions of the U.S., including those with large Hispanic, black, and Asian populations. Although not a representative sample of the entire U.S. population, cases came from seven cancer registries covering defined geographic regions of the country, including five registries with statewide coverage. The overall HPV prevalence of $63 \%$ in this U.S. sample is higher than estimates of HPV prevalence in penile cancers worldwide (2, $3,5)$. Two reviews of published studies of penile cancers diagnosed worldwide in 1986-2008 found an overall HPV prevalence of $47-48 \%(2,5)$. Differences in the sensitivity of laboratory methods may account for a higher prevalence in our study population. Notably, the present study utilized methods designed to enhance DNA isolation from fixed, archival tissue, and two separate PCR-based genotyping assays detecting a broad range of HPV genotypes. HPV prevalence may have also been influenced by unmeasured factors specific to the study population such as sexual risk factors and circumcision status.

Our findings agree with previous studies demonstrating HPV 16 to be the predominant genotype in penile cancers $(2,6,7)$. HPV 16 and 18 , the two high-risk types covered by current prophylactic vaccines, were identified in nearly half of the tumors. The potential role of other genotypes in penile carcinogenesis is underscored by the detection of 14 other types, including those considered to be low-risk. The detection of low-risk types HPV 6 and 42 alone in a small proportion of penile tumors is consistent with previous studies and may be indicative of the rare carcinogenic potential of these types $(5,22-24)$.

Regional and racial/ethnic disparities in the incidence of penile cancer have been observed in the U.S. with higher incidence in the South and among blacks and Hispanics and lower incidence in the West and among Asian-Pacific Islanders $(1,25,26)$. In our limited sample, we observed no differences between HPV-positive and HPV-negative penile cancer cases by age, race/ethnicity, or population size of geographic region.

We also observed no significant differences in HPV status by stage, histology, grade, or penile subsite. Notably, nearly all basaloid and warty tumors, including mixed subtypes, were HPV-positive. This is consistent with previous studies demonstrating a higher prevalence of HPV in these histological types $(2,4,7)$.

The incidence of invasive penile cancer in the U.S. has significantly declined over the past several decades $(25,26)$. The reason for this decline is unknown but may be attributed to population-level changes including decreases in smoking rates (27) and increases in circumcision in older birth cohorts (28). A major limitation of this study is the lack of patient information on other risk factors for penile cancer including sexual history, smoking, circumcision, and phimosis $(4,8-11)$. This information is generally not abstracted by cancer registries. The availability of such data would permit a more comprehensive evaluation of the role of HPV relative to these factors.

Human papillomavirus was detected more frequently in the recently diagnosed cases. A recent study reported that the prevalence of HPV in U.S. oropharyngeal cancers significantly increased over calendar time from 1984 to 2004 (29). It was surmised that this may reflect increases in high-risk sexual activity and HPV exposure over time. The authors corrected for potential loss in assay sensitivity with specimen age. In the present study, prevalence estimates were not corrected. Therefore, it is possible that the observed temporal differences in HPV prevalence were an artifact due to the relative age of the archival tissue specimens. That is, viral DNA may have been less readily detected in older specimens due to degradation of nucleic acid in preserved tissue over time. While we found no evidence for this, it is hard to completely exclude this explanation. The ability to examine temporal trends in the present study is limited by the relatively narrow ( 8 year) period of diagnosis of cases. In addition, because registries used different temporal sampling frames, it is possible that observed temporal differences reflect geographic differences. In the present study, HPV prevalence is not presented by registry to protect patient confidentiality given the small number of cases.

In patients with oropharyngeal cancer HPV tumor positivity predicts a favorable outcome, including overall survival and 
disease-free survival (30-36). Few studies have examined the role of HPV in penile cancer survival. Lont et al. (6) observed that penile cancer patients with high-risk human HPV had significantly higher 5-year survival, and HPV was an independent predictor of survival after adjustment for age and clinical characteristics (6). We found no association of HPV status, including any HPV and HPV 16, with penile cancer survival.

As with other PCR-based studies, we cannot be certain that the HPV DNA detected was present and causal in the tumor. HPV infection could have been present in nearby tissue. Evaluation of other molecular markers of HPV, including p16 ${ }^{\text {INK4a }}$ and E6/E7 mRNA, may provide important insight into the clinical relevance of viral detection in penile cancers (37).

Forty-eight percent of penile cancers were positive for HPV 16 or 18 , which are included in current vaccines. HPV vaccination has demonstrated high efficacy for the prevention of genital HPV infection and external genital lesions in males (38). Nonetheless, vaccine efficacy for the prevention of penile cancers has not yet been directly evaluated in clinical trials.

The relatively high prevalence of HPV in our study population provides limited evidence of a more prominent and, possibly, increasing role of infection in penile carcinogenesis in the U.S. compared to other parts of the world. Population differences in the prevalence of sexual risks, circumcision, and other factors influencing HPV acquisition and persistence may account for these results. Our findings would be bolstered by future U.S. studies which include larger, population-based samples, which are derived from patients diagnosed with penile cancer over a wider time period.

\section{ACKNOWLEDGMENTS}

We thank all members of HPV Typing of Cancers Workgroup:

$C D C$ :

Mona Saraiya, MD, MPH, CDC, Division of Cancer Prevention and Control; Elizabeth R. Unger, MD, Ph.D., CDC, CCID/NCEZID/DHCPP/CVDB; Martin Steinau, Ph.D., CDC, CCID/NCEZID/DHCPP/CVDB; Mariela Z. Scarbrough, BS, CCID/NCEZID/DHCPP/CVDB; Meg Watson, MPH, Division of Cancer Prevention and Control; Trevor Thompson, BS, CDC, Division of Cancer Prevention and Control; Deblina Datta, MD, Division of STD Prevention; Susan Hariri, Ph.D., Division of STD Prevention.

\section{Battelle:}

Christopher Lyu, MPA, Battelle, Durham, NC; Bruce Ellis, MS, Battelle, Arlington, VA; Natalie Madero, BS, Battelle, Baltimore, MD; Emily Reid, BA, Battelle, Durham, NC; Donna Little, BS, Battelle, Baltimore, MD; April Greek, Ph.D., Battelle, Seattle, WA; Dale Rhoda, Ph.D., Battelle, Columbus, OH; Susan Brossoie, CTR/RHIT, UNC Hospitals Cancer Registry, Chapel Hill, NC; Katherine Gideon, Battelle, Toxicology Northwest, Richland, WA; Linda Delma Gieseke, Battelle, Columbus, OH; Stephanie Ashcraft, Battelle, Columbus, $\mathrm{OH}$.

Florida:

Jill MacKinnon, Ph.D., University of Miami, Florida Cancer Data System; Youjie Huang, MD, DrPH, MPH, Florida State
Department of Health; Carlos Alvarez, BBA, University of Miami, Florida Cancer Data System; Edward Wilkinson, MD, University of Florida; Martha Campbell-Thompson, DVM, Ph.D., University of Florida; Amy Wright, MS, University of Florida; Kelley Durden, HT (ASCP), University of Florida.

\section{Hawaii:}

Brenda Hernandez, Ph.D., University of Hawaii, Cancer Research Center of Hawaii; Marc Goodman, Ph.D., University of Hawaii, Cancer Research Center of Hawaii; Hugh Luk, BS, HTL, University of Hawaii, Cancer Research Center of Hawaii; David Horio, MD, University of Hawaii, Cancer Research Center of Hawaii; Shoji Ikeda, BA, University of Hawaii, Cancer Research Center of Hawaii; Michael Green, CTR, University of Hawaii, Cancer Research Center of Hawaii; Catherine Grafel-Anderson, BS, University of Hawaii, Cancer Research Center of Hawaii; Rayna Weise, MPH, University of Hawaii, Cancer Research Center of Hawaii.

Iowa:

Freda Selk, AAS, University of Iowa; Dan Olson, MS, University of Iowa.

\section{Kentucky:}

Thomas Tucker, Ph.D., MPH, University of Kentucky; Claudia Hopenhayn, Ph.D., MPH, University of Kentucky; Amy Christian, MSPH, University of Kentucky.

\section{Louisiana:}

Edward Peters, DMD, SM, ScD, Louisiana State University; Lauren Cole, Ph.D., MPH Candidate, Louisiana State University; Tara Ruhlen, MPH, Carolinas Rehabilitation, Charlotte, NC.

Los Angeles County, California:

Joe House, University of Southern California; Myles G. Cockburn, Ph.D., University of Southern California; Andre Kim, MPH, University of Southern California.

Michigan:

Glenn Copeland, MS, Michigan Department of Community Health; Lana Ashley, Michigan Department of Community Health; Jetty Alverson, Michigan Department of Community Health; Michelle Hulbert, Michigan Department of Community Health; Won Silva, MA, Michigan Department of Community Health; Samuel Hirsch, MD, St Joseph Mercy Hospital, Ann Arbor, Michigan.

\section{Financial Support:}

This project was supported in part by the Centers for Disease Control and Prevention (CDC) cooperative agreement NO. 5U58DP000810-5 (Kentucky), 5U58DP000844-5 (Florida), 5U58DP000812-5 (Michigan), and 5U58DP000769-5 (Louisiana) and from the SEER Program, National Institutes of Health, Department of Health and Human Services, under Contracts N01-PC-35139 (Los Angeles), N01-PC-35143 (Iowa), and N01PC-35137 (Hawaii). The support for collection of specimens from Kentucky, Florida, Michigan, and Louisiana, coordination of genotyping data from both SEER and NPCR registries, and genotyping was largely supported by CDC intramural funds and Vaccine for Children Funds. The collection of data from California was largely supported by the California Department of Health Services as part 
of the statewide cancer reporting program mandated by California Health and Safety Code Section 103885; by the National Cancer Institute, National Institutes of Health, Department of Health and Human Services under Contract N01-PC-2010-00035; and cooperative agreement number 1U58DP000807-3 from the Centers for Disease Control and Prevention. The findings and conclusions in this report are those of the authors and do not necessarily represent the official position of the Centers for Disease Control and Prevention. Disclosures: Brenda Y. Hernandez has received consultation from Merck and Co., Inc., for activities unrelated to this project.

\section{REFERENCES}

1. Hernandez BY, Barnholtz-Sloan J, German RR, Giuliano A, Goodman MT, King JB, et al. Burden of invasive squamous cell carcinoma of the penis in the United States, 1998-2003. Cancer (2008) 113(10 Suppl):2883-91. doi:10.1002/ cncr. 23743

2. Backes DM, Kurman RJ, Pimenta JM, Smith JS. Systematic review of human papillomavirus prevalence in invasive penile cancer. Cancer Causes Control (2009) 20(4):449-57. doi:10.1007/s10552-008-9276-9

3. Parkin DM, Bray F. Chapter 2: the burden of HPV-related cancers. Vaccine (2006) 24(Suppl 3):S3/11-25. doi:10.1016/j.vaccine.2006.05.111

4. Rubin MA, Kleter B, Zhou M, Ayala G, Cubilla AL, Quint WG, et al. Detection and typing of human papillomavirus DNA in penile carcinoma: evidence for multiple independent pathways of penile carcinogenesis. Am J Pathol (2001) 159(4):1211-8. doi:10.1016/S0002-9440(10)62506-0

5. Miralles-Guri C, Bruni L, Cubilla AL, Castellsague X, Bosch FX, de Sanjose S. Human papillomavirus prevalence and type distribution in penile carcinoma. $J$ Clin Pathol (2009) 62(10):870-8. doi:10.1136/jcp.2008.063149

6. Lont AP, Kroon BK, Horenblas S, Gallee MP, Berkhof J, Meijer CJ, et al. Presence of high-risk human papillomavirus DNA in penile carcinoma predicts favorable outcome in survival. Int J Cancer (2006) 119(5):1078-81. doi:10.1002/ijc.21961

7. Chaux A, Netto GJ, Rodríguez IM, Barreto JE, Oertell J, Ocampos S, et al. Epidemiologic profile, sexual history, pathologic features, and human papillomavirus status of 103 patients with penile carcinoma. World J Urol (2011) 31(4):861-7. doi:10.1007/s00345-011-0802-0

8. Maden C, Sherman KJ, Beckmann AM, Hislop TG, Teh CZ, Ashley RL, et al. History of circumcision, medical conditions, and sexual activity and risk of penile cancer. J Natl Cancer Inst (1993) 85(1):19-24. doi:10.1093/jnci/85.1.19

9. Brinton LA, Li JY, Rong SD, Huang S, Xiao BS, Shi BG, et al. Risk factors for penile cancer: results from a case-control study in China. Int J Cancer (1991) 47(4):504-9. doi:10.1002/ijc.2910470406

10. Daling JR, Madeleine MM, Johnson LG, Schwartz SM, Shera KA, Wurscher MA, et al. Penile cancer: importance of circumcision, human papillomavirus and smoking in in situ and invasive disease. Int J Cancer (2005) 116(4):606-16. doi:10.1002/ijc.21009

11. Tsen HF, Morgenstern H, Mack T, Peters RK. Risk factors for penile cancer: results of a population-based case-control study in Los Angeles County (United States). Cancer Causes Control (2001) 12(3):267-77. doi:10.1023/A:1011266405062

12. Cupp MR, Malek RS, Goellner JR, Smith TF, Espy MJ. The detection of human papillomavirus deoxyribonucleic acid in intraepithelial, in situ, verrucous and invasive carcinoma of the penis. J Urol (1995) 154(3):1024-9. doi:10.1016/S0022-5347(01)66967-2

13. Varma VA, Sanchez-Lanier M, Unger ER, Clark C, Tickman R, Hewan-Lowe $\mathrm{K}$, et al. Association of human papillomavirus with penile carcinoma: a study using polymerase chain reaction and in situ hybridization. Hum Pathol (1991) 22(9):908-13. doi:10.1016/0046-8177(91)90181-N

14. Wiener JS, Effert PJ, Humphrey PA, Yu L, Liu ET, Walther PJ. Prevalence of human papillomavirus types 16 and 18 in squamous-cell carcinoma of the penis: a retrospective analysis of primary and metastatic lesions by differential polymerase chain reaction. Int J Cancer (1992) 50(5):694-701. doi:10.1002/ ijc. 2910500505

15. Carter JJ, Madeleine MM, Shera K, Schwartz SM, Cushing-Haugen KL, Wipf GC, et al. Human papillomavirus 16 and $18 \mathrm{~L} 1$ serology compared across anogenital cancer sites. Cancer Res (2001) 61(5):1934-40.
16. Gargano JW, Wilkinson EJ, Unger ER, Steinau M, Watson M, Huang Y, et al. Prevalence of human papillomavirus types in invasive vulvar cancers and vulvar intraepithelial neoplasia 3 in the United States before vaccine introduction. J Low Genit Tract Dis (2012) 16(4):471-9. doi:10.1097/LGT. 0b013e3182472947

17. Fritz A, Percy C, Shanmugaratnam K, et al. The International Classification of Diseases for Oncology. 3rd ed. Geneva: World Health Organization (2000).

18. Goodman MT, Hernandez BY, Hewitt S, Lynch CF, Coté TR, Frierson HF Jr, et al. Tissues from population-based cancer registries: a novel approach to increasing research potential. Hum Pathol (2005) 36(7):812-20. doi:10.1016/j.humpath. 2005.03.010

19. Steinau M, Patel SS, Unger ER. Efficient DNA extraction for HPV genotyping in formalin-fixed, paraffin-embedded tissues. J Mol Diagn (2011) 13(4):377-81. doi:10.1016/j.jmoldx.2011.03.007

20. Young JL Jr, Roffers SD, Ries LAG, Fritz AG, Hurlbut AA editors. SEER Summary Staging Manual - 2000: Codes and Coding Instructions. Bethesda, MD: National Cancer Institute (2001).

21. IARC. Human papillomaviruses. IARC Monogr Eval Carcinog Risks Hum (2007) 90:1-636.

22. Senba M, Kumatori A, Fujita S, Jutavijittum P, Yousukh A, Moriuchi T, et al. The prevalence of human papillomavirus genotypes in penile cancers from northern Thailand. J Med Virol (2006) 78(10):1341-6. doi:10.1002/jmv.20703

23. Heideman DA, Waterboer T, Pawlita M, Delis-van DiemenP, Nindl I, Leijte JA, et al. Human papillomavirus-16 is the predominant type etiologically involved in penile squamous cell carcinoma. JClin Oncol (2007) 25(29):4550-6. doi:10.1200/JCO.2007.12.3182

24. Guimerà N, Lloveras B, Lindeman J, Alemany L, van deSandtM, Alejo M, et al. The occasional role of low-risk human papillomaviruses $6,11,42,44$, and 70 in anogenital carcinoma defined by laser capture microdissection/PCR methodology: results from a global study. Am J Surg Pathol (2013) 37(9):1299-310. doi:10.1097/PAS.0b013e31828b6be4

25. Goodman MT, Hernandez BY, Shvetsov YB. Demographic and pathologic differences in the incidence of invasive penile cancer in the United States, 19952003. Cancer Epidemiol Biomarkers Prev (2007) 16(9):1833-9. doi:10.1158/ 1055-9965.EPI-07-0221

26. Barnholtz-Sloan JS, Maldonado JL, Pow-sang J, Guiliano AR. Incidence trends in primary malignant penile cancer. Urol Oncol (2007) 25(5):361-7. doi:10.1016/ j.urolonc.2006.08.029

27. From the Centers for Disease Control and Prevention. Cigarette smoking among adults - United States, 1991. JAMA (1993) 269(15):1931.

28. Xu F, Markowitz LE, Sternberg MR, Aral SO. Prevalence of circumcision and herpes simplex virus type 2 infection in men in the United States: the National Health and Nutrition Examination Survey (NHANES), 1999-2004. Sex Transm Dis (2007) 34(7):479-84.

29. Chaturvedi AK, Engels EA, Pfeiffer RM, Hernandez BY, Xiao W, Kim E, et al. Human papillomavirus (HPV) and rising oropharyngeal cancer incidence in the United States. J Clin Oncol (2011) 29(32):4294-301. doi:10.1200/JCO.2011.36. 4596

30. Ang KK, Harris J, Wheeler R, Weber R, Rosenthal DI, Nguyen-Tân PF, et al. Human papillomavirus and survival of patients with oropharyngeal cancer. $N$ Engl J Med (2010) 363(1):24-35. doi:10.1056/NEJMoa0912217

31. Mellin H, Friesland S, Lewensohn R, Dalianis T, Munck-Wikland E. Human papillomavirus (HPV) DNA in tonsillar cancer: clinical correlates, risk of relapse, and survival. Int J Cancer (2000) 89(3):300-4. doi:10.1002/10970215(20000520)89:3<300::AID-IJC14>3.0.CO;2-G

32. Ritchie JM, Smith EM, Summersgill KF, Hoffman HT, Wang D, Klussmann JP, et al. Human papillomavirus infection as a prognostic factor in carcinomas of the oral cavity and oropharynx. Int J Cancer (2003) 104(3):336-44. doi:10.1002/ijc. 10960

33. Li W, Thompson CH, O'Brien CJ, McNeil EB, Scolyer RA, Cossart YE, et al. Human papillomavirus positivity predicts favourable outcome for squamous carcinoma of the tonsil. Int J Cancer (2003) 106(4):553-8. doi:10.1002/ijc.11261

34. Fakhry C, Westra WH, Li S, Cmelak A, Ridge JA, Pinto H, et al. Improved survival of patients with human papillomavirus-positive head and neck squamous cell carcinoma in a prospective clinical trial. J Natl Cancer Inst (2008) 100(4):261-9. doi:10.1093/jnci/djn011

35. Kumar B, Cordell KG, Lee JS, Worden FP, Prince ME, Tran HH, et al. EGFR, p16, HPV Titer, Bcl-xL and p53, sex, and smoking as indicators of response to therapy 
and survival in oropharyngeal cancer. J Clin Oncol (2008) 26(19):3128-37. doi:10.1200/JCO.2007.12.7662

36. Licitra L, Perrone F, Bossi P, Suardi S, Mariani L, Artusi R, et al. High-risk human papillomavirus affects prognosis in patients with surgically treated oropharyngeal squamous cell carcinoma. J Clin Oncol (2006) 24(36):5630-6. doi:10.1200/JCO.2005.04.6136

37. Cubilla AL, Lloveras B, Alejo M, Clavero O, Chaux A, Kasamatsu E, et al. Value of p16(INK)(4)(a) in the pathology of invasive penile squamous cell carcinomas: a report of 202 cases. Am J Surg Pathol (2011) 35(2):253-61. doi:10.1097/PAS.0b013e318203cdba

38. Giuliano AR, Palefsky JM, Goldstone S, Moreira ED Jr, Penny ME, Aranda C, et al. Efficacy of quadrivalent HPV vaccine against HPV Infection and disease in males. N Engl J Med (2011) 364(5):401-11. doi:10.1056/NEJMoa0909537

Conflict of Interest Statement: Brenda Y. Hernandez has received consultation from Merck and Co., Inc., for activities unrelated to this research project. The other coauthors declare that the research was conducted in the absence of any commercial or financial relationships that could be construed as a potential conflict of interest.
Received: 31 October 2013; paper pending published: 28 November 2013; accepted: 17 January 2014; published online: 05 February 2014.

Citation: Hernandez BY, Goodman MT, Unger ER, Steinau M, Powers A, Lynch CF, Cozen W, Saber MS, Peters ES, Wilkinson EJ, Copeland G, Hopenhayn C, Huang Y, Watson M, Altekruse SF, Lyu C, Saraiya $M$ and The HPV Typing of Cancer Workgroup (2014) Human papillomavirus genotype prevalence in invasive penile cancers from a registry-based United States population. Front. Oncol. 4:9. doi: 10.3389/fonc.2014.00009

This article was submitted to Cancer Epidemiology and Prevention, a section of the journal Frontiers in Oncology.

Copyright $\odot 2014$ Hernandez, Goodman, Unger, Steinau, Powers, Lynch, Cozen, Saber, Peters, Wilkinson, Copeland, Hopenhayn, Huang, Watson, Altekruse, Lyu, Saraiya and The HPV Typing of Cancer Workgroup. This is an open-access article distributed under the terms of the Creative Commons Attribution License (CC BY). The use, distribution or reproduction in other forums is permitted, provided the original author(s) or licensor are credited and that the original publication in this journal is cited, in accordance with accepted academic practice. No use, distribution or reproduction is permitted which does not comply with these terms. 